
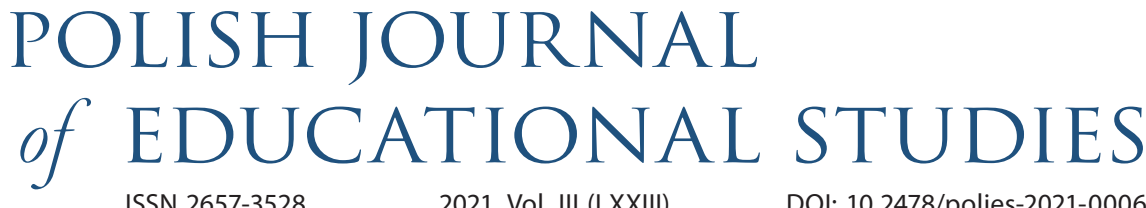

\title{
Moving Towards Greater Inclusion in Singapore's Preschools: The Enablers, Possibilities and Barriers
}

\author{
Sophia C.F. Goh ${ }^{1}$ and Shi Yue Tan ${ }^{2}$
}

\begin{abstract}
Inclusive education is the next item on the agenda of policy makers in Singapore, in its striving to provide quality education for all children. The move to introducing more inclusive practices in preschools has not been easy. There are many structural obstacles in Singapore's current preschool context. This review of existing literature on this topic reveals how policymakers, schools, teachers, and parents need to work together to create a successful inclusive education system. There is much that Singapore must work on to develop a successful inclusive preschool education model. The paper aims to provide an understanding of how inclusion in preschools can be more effectively practiced in Singapore by considering the current dual education system in Singapore and the recent measures introduced to improve inclusive preschool education. It examines how effective these measures and recommendations in existing literature will be when placed in Singapore's current education system which prioritizes academic excellence. In doing so, this paper hopes to highlight the critical issues that policymakers and key stakeholders should consider when planning for inclusive practices in Singapore's preschools.
\end{abstract}

KEYWORDS:

inclusion, special education, preschool, Singapore, early years, inclusive practices

\section{Introduction}

The importance of quality preschool education and care is recognized widely by many countries, including Singapore (Tan, 2017). As Singapore progresses forward

1 University of Northampton, United Kingdom E-MAlL: sophia.goh93@gmail.com

2 University of Northampton, United Kingdom E-MAIL: sytan045@gmail.com ORCID: 0000-0002-8864-6695 
with increasing the quality of preschool education and care, it is pertinent that children with special needs are not being left behind. Over the last few years, Singapore has touched on the issue of inclusion in mainstream schools by proposing initiatives to ready schools for including children with special needs. As such, this desk-based research seeks to explore the factors that enable inclusion, and the challenges Singapore faces in making preschools more inclusive.

This paper starts with offering an understanding of inclusion, followed by discussing the benefits and disadvantages of inclusive preschool education. Next, it discusses factors that enable inclusion to succeed. It then delves into Singapore's context, looking at the current situation and the initiatives made by the government to promote inclusive preschool education. Following this, the barriers that Singapore faces in moving towards a more inclusive preschool education will be considered. Lastly, this paper will end with a personal reflection of the lead author on her experience with including children with special needs as a preschool teacher in Singapore.

\section{Inclusion: What does it mean?}

Inclusion, in the context of education, can be loosely defined as the practice of educating students with special needs in mainstream schools (Yeo et al., 2016). Key concepts of inclusion include: education for all, full-time participation, and support.

\section{Education for all}

When discussing inclusive education, common terminology used to refer to the group of individuals being excluded include "children with special needs" and "children with disabilities". These umbrella terms refer to children with disabilities, for example, physical disabilities, developmental disabilities such as autism spectrum disorder or global developmental delay, and visual or hearing impairments. However, when we use these terms, we end up neglecting the children who are being marginalized by the education system, such as refugees, minorities, and children from low-income families (Opertti et al., 2013). It is important that all children are included when we view the larger picture of inclusion (Walker \& Musti-Rao, 2016). Inclusion within schools also has wider implications by serving as a foundation for building an inclusive society (Walker \& Musti-Rao, 2016). In Singapore's context, it is equally important to ensure children from low-income families are included in mainstream schools. However, Singapore has already made significant progress in this regard and children from low-income families face less of an issue being included with much financial support being provided through subsidies and welfare packages (Ang et al., 2021). Hence, this paper will solely focus on inclusion for children with special needs. 


\section{Full-time participation and support}

Inclusion is understood and practiced differently across countries (Yeo et al., 2016). Over time, several countries have gone beyond the placement concept of inclusion, where children with mild to moderate disabilities and children with special needs are in the class but are not socially accepted by their peers (Yeo et al., 2011). This acknowledges the importance of the social dimension of inclusion where children with special needs are considered part of the school community and full-time participants (Yeo et al., 2016), as well as gain a sense of belonging in the school (Karlsudd, 2021). Thus, schools which practice inclusion by building a special school for children with special needs within the compounds of a mainstream school, may not be considered inclusive since the social dimension of inclusion is lacking.

A more practiced form of inclusion is the learning concept where children with special needs learn together with their typically developing peers and are considered full-time participants of the class and school (Yeo et al., 2011). Their contributions in class are valued and they are included in all those lessons which they can learn best in. Support may also be provided through a pull-out system where children with special needs receive additional assistance or individualized instructions in class or are pulled out for additional support through a modified curriculum or additional programs (Yeo et al., 2016). Teacher aides, such as shadow teachers, may also be present to assist children with different learning needs as well. Hence, this form of inclusion offers either full or partial inclusion, where children with special needs are still being educated alongside their typically developing peers for most of the day.

Nevertheless, the additional support for children with special needs may serve as a barrier to inclusion. A teacher aide helps to provide the support that children with special needs require and relieves some of the burden of the main teacher. However, they can also work towards excluding children with special needs when the main teacher relinquishes responsibility for the children with special needs (Ainscow, 2000). In this scenario, children with special needs become overly reliant on the teacher aide and this minimizes their social interactions with the main teacher and their typically developing peers. Hence, it does not meet the purpose of inclusion where children with special needs interact and learn together with typically developing children.

To prevent potentially excluding children with special needs, some schools have worked out ways to provide additional support for children with special needs while trying to ensure that all children receive equal support (Andresen, 2013). While additional support is provided with the presence of additional manpower, teachers are not solely responsible for assisting children with special needs, but rather everyone in the class. Furthermore, by assigning each child a contact teacher whom they can approach when they require assistance, children with special needs are not perceived as different and this helps in improving inclusive practices (Andreson, 2013). Instead, 
this could be considered real inclusion where children with special needs are included into a mainstream class, both physically and socially, being seen as equals.

Inclusive education thus requires a transformation of current school practices and policies (Yeo et al., 2016), to better support the needs for all students (Weng et al., 2015). The schools need to assume responsibility for all students, with or without disabilities, in ensuring quality education for all. Disability is no longer the issue, rather, the issue lies with the environment not being a good fit to support the needs of individuals (Yeo et al., 2016). Overall, inclusive education means a radical change to all students being educated together, as members of the school community and receiving the support they need for to ensure quality education.

\section{The debate: Inclusion or exclusion?}

Moving towards inclusion in education can be difficult and daunting for schools and school staff. Hence, why there is such a strong push for inclusion. Apart from the potential benefits and issues arising from including children with special needs, we should also consider a key factor, the rights of all students to education.

\section{Benefits of and issues with inclusion}

Benefits of inclusion include the acquisition of social and communication skills through interactions with typically developing peers. Peer interactions are paramount for children to acquire certain language or cognitive skills (Tan \& Perren, 2021). Through peer interactions, children with special needs exchange ideas and feelings through verbal and/or non-verbal communication with typically developing peers. Their peers also serve as models for them to pick up positive behaviors and social skills. The positive impact that interacting with typically developing children has on children with special needs, is supported by Justice et al.'s (2014) study where they observed that children learnt by first observing and imitating before internalizing and modelling the behavior of more competent peers. In addition, their language skills were positively influenced by their peers.

However, Li and Chong's (2011) paper highlighted that there is a low frequency of interactions between typically developing children and children with special needs in inclusive settings without facilitation. Still, they point out that it is beneficial for children with special needs to be included into mainstream preschool. That is because apart from direct instructions from teachers, inclusive settings allow for opportunities for incidental learning, where both children with special needs and typically developing peers learn about positive behaviours and are rewarded when performing them ( $\mathrm{Li}$ \& Chong, 2011). This positive reinforcement, coupled with facilitation from preschool 
teachers, enhances the quality of interactions between children with special needs and their typically developing peers, which cannot be gained from purely attending a special education school.

While most parents of children with mild special needs prefer for them to be schooled in mainstream settings, some parents of children with moderate to severe disabilities have expressed reservations over inclusion (Wong et al., 2015). These parents are concerned about the willingness and ability of the school to accommodate their child's needs, as well as the teachers' competency in managing their child's behavior and educating them. In addition, parents are also worried that their child may be impacted by the negative societal stereotypes of persons with disabilities. These concerns are not unfounded especially because in Singapore, schools are academiccentric and have a high teacher-child ratio (Wong et al., 2015). As such, some parents of children with moderate to severe disabilities prefer for their child to attend special schools where they would be able to receive more individualized support (Wong et al., 2015; Yang \& Rusli, 2011).

Nonetheless, children with severe disabilities do gain from inclusion, with marked improvements in their developmental outcomes as compared to children with severe disabilities who were educated only in special schools (Yang \& Rusli, 2011). In inclusive settings, typically developing peers serve as role models by displaying age-appropriate behaviors. With opportunities for communication and social interactions, even children with severe disabilities have shown improvements in their language development, social and academic skills, and behavior. Furthermore, typically developing children benefit as well when they learn to be more accepting, sympathetic, and tolerant of their peers with special needs. With teachers trained with effective inclusion strategies, children with severe disabilities have forged friendships with their typically developing children (Yang \& Rusli, 2011).

Although most teachers in Singapore are supportive of inclusion (Nonis et al., 2016), there are teachers who view inclusion as an issue when typically developing children learn 'undesirable' behaviors from children with special needs (Nonis, 2006). This group of teachers who do not agree with inclusion, are of the opinion that children with special needs can be disruptive to lessons, especially when their behavior cannot be managed. Along with structural barriers, such as a high teacher-child ratio, lack of training on managing children with special needs, inclusion can prove to be daunting and more of an issue than beneficial (Yeo et al., 2011).

However, Nonis (2006) also points out that teachers who were less accepting of inclusion had a lack of understanding of children with special needs. These negative perceptions can also be reflective of the concerns and insecurities that teachers hold towards their ability to work with children with special needs effectively (Poon et al., 2016). It results in teachers being anxious and resistant towards inclusion. With train- 
ing on inclusion for teachers and exposure to children with special needs, teachers will gain greater confidence in managing children with special needs and hence become more supportive of inclusion (Poon et al., 2016). Circumventing these perceived disadvantages hence requires that teachers are trained to play an active role in facilitating positive interactions between children with special needs and their typically developing peers.

\section{The right to education}

Inclusion is based on the premise that every child has the right to receive education in an inclusive environment, where policy makers and teachers are supportive of inclusive practices in mainstream schools (Opertti et al., 2013). A child's right to education in Singapore dates back to the 1999 Convention on the Rights of the Child, which proposes that schools provide education that does not discriminate based on disability. Thus, each child is entitled to access to a mainstream school which offers a curriculum that enables them to maximize their potential (Opertti et al., 2013).

Singapore has acceded to the 1995 United Nations Convention on the Rights of the Child and signed the United Nations Convention on the Rights of Persons with Disabilities in 2013 (Lipponen \& Ang, 2019). Hence, policy makers are working towards building a more inclusive education system and hence a more inclusive society. Nevertheless, progress has been slow with improving inclusive preschool education. Thus, we will next look at how inclusive education can be successfully practiced in preschools.

\section{Factors enabling inclusion in preschools}

\section{The role of a teacher}

Merely placing children with special needs in mainstream classes will not enable them to reap the benefits of inclusion. Without a teacher's facilitation, there may be lower frequency of interactions between children with special needs and typically developing children (Li \& Chong, 2011). Furthermore, some children with autism spectrum disorder or developmental disabilities, have deficits in imitating teachers and their peers (Garfinkle \& Schwartz, 2002). Teachers hence play a big role in facilitating positive interactions between children, modelling, and reinforcing desirable behaviors.

For inclusion to be successful, it is paramount that teachers hold positive attitudes towards inclusion and are trained to manage children with special needs (Akalin et al., 2014; Karlsudd, 2021; Poon et al., 2016). Teachers who are empathetic, committed, and respectful serve as great role models allowing typically developing children to gain greater compassion, understanding and show respect towards their peers with special 
needs (Karlsudd, 2021). While teachers interviewed about their perspectives on inclusion held generally positive attitudes towards inclusion, most of them mentioned their concerns about the quality of inclusive education given their limited knowledge on inclusion and special needs (Akalin et al., 2014; Nonis et al., 2016). Hence, training must be provided for both in-service and pre-service teachers to provide more information and knowledge.

Specifically, some teachers have pointed out that on-the-job training would be more helpful, as compared to a one-off training session, since it allows them to gain the skills needed to support children with special needs (Akalin et al., 2014; Karlsudd, 2021). In addition, exposure to children with special needs make a big difference, given the differences between individuals. A behavioral management strategy that works for one child may not work for another, hence in reality, many teachers only gain knowledge and experiences via trial and error (Akalin et al., 2014).

With greater knowledge and experience working with children with special needs, teachers have become more supportive of inclusive efforts in their classes (Karlsudd, 2021; Nonis et al., 2016). The positive attitude they carry, shows in their commitment to include and the respect they show to children with special needs. Inclusion is not an easy job, it requires much planning and revising of the curriculum, setting up an inclusive environment, hours of professional development and working with early intervention professionals and parents. Only with a positive attitude towards inclusion, with a focus on strengths rather than disabilities, will inclusion succeed.

\section{Creating an inclusive environment}

A desirable inclusive environment is one which enables children to feel a sense of belonging, build positive social relationships and friendships, and learn and develop to their fullest potential (Xie et al., 2021). This requires schools to be restructured to provide comprehensive support for all children (Opertti et al., 2013). Adaptations must be made to suit the needs of the children, and this can be achieved through revising existing curriculums to design one that they accommodate the learning needs for all children. Teachers also need to ensure that children with special needs are not being left out by their peers during playtime, lessons, and mealtimes (Tan \& Perren, 2021). With comprehensive support, individualized adaptations, and healthy interactions with typically developing peers, children with special needs can feel a sense of belonging and become valued participants in their classes (Brodzella et al., 2017; Xie et al., 2021).

Apart from the physical and social environment, it is crucial that teachers receive support from early intervention professionals and the school. Barriers to inclusion, according to teachers, are lack of professional knowledge on inclusion and special needs and the shortage of manpower to manage children with special needs by 
themselves (Akalin et al., 2014; Nonis et al., 2016). Collaboration with early intervention professionals who could coach or mentor teachers, will enable teachers to better understand, manage children with special needs and develop individual education plans for them (Nonis et al., 2016). This also allows children to receive the early intervention and support they require from professionals within the preschool (Opertti et al., 2013). Furthermore, when there is school-wide collaboration, it allows teachers to pick up behavioral management strategies from their colleagues and work together to create a more inclusive environment (Yeo et al., 2016). Hence, increased collaboration with early intervention professionals and colleagues allows teachers to successfully design and ensure an inclusive environment for children with special needs.

\section{Partnership with parents}

For inclusion to be successful, teachers have mentioned that maintaining an active partnership with parents is important (Tan \& Perren, 2021; Karlsudd, 2021). By collaborating with parents, teachers can better understand the child with special needs as well as the parents' concerns for their child. Behavioral management strategies being practiced at home for the child can be continued in school, and vice versa (Tan \& Perren, 2021). This assists teachers in their planning of the curriculum, lessons, environment, and individual education plan for the child. With parents reinforcing what teachers have taught in schools, children with special needs can achieve improved developmental outcomes (Yeo et al., 2016).

\section{The government's support}

There is only so much that a teacher and the school can do. It is necessary for them to be supported by the government for inclusion to be successful. With the government's support, schools can get more funding and resources to secure facilities that support the needs of their students as well as for teachers to engage in more professional development to build up their competency and confidence in working with children with special needs (Yeo et al., 2016). In addition, policy makers decide the teacher-child ratio. One barrier to inclusion is a high teacher-child ratio and lack of additional manpower to assist teachers in managing the class (Akalin et al., 2014; Yeo et al., 2016; Nonis et al., 2016), hence concern regarding whether children with special needs are receiving quality education. Thus, when governments, schools and teachers are aligned in their vision for an inclusive education system, more changes and support can be provided to ensure a successful inclusion program.

Having established that inclusion requires all stakeholders to work together to create a successful inclusive education system, we will now look at the current context in Singapore and the measures taken. 


\section{Singapore's Context}

While there is no legislation on the inclusion of children with special needs in mainstream schools, the Advisory Council for the Disabled has pushed for special education to be provided within the mainstream education system with children only placed in special schools if they cannot receive quality education in mainstream schools (Wong et al., 2015). In moving towards inclusion, policy makers are guided by recommendations made by Enabling Masterplans, which are five-year roadmaps towards building an ecosystem of support for people with disabilities (Third Enabling Masterplan Steering Committee, 2016). The third, and current, Enabling Masterplan for 2017 to 2021 places emphasis on early detection and access to quality education in mainstream schools for children with special needs, to build an inclusive society and change mindsets.

However, Singapore's curriculum which focuses on academic excellence has meant that children with special needs are being left out in fear that they would not be able to cope well in mainstream schools (Wong et al., 2015). As such, Singapore currently practices a dual education system with mainstream schools for typically developing children and children with mild special needs, and special education schools for children with moderate to severe special needs (Poon \& Yang, 2016). The level of inclusion in mainstream schools is dependent on the severity of the child's disability and the amount of support available in the school to provide quality education for the child (Wong et al., 2015). Although preschools are not as academic-centric as mainstream primary schools, a dual education system is still being practiced as mainstream preschools are not structured to provide the support that children with special needs require and teachers are not trained in special needs. In mainstream preschools, center leaders will decide if they will accept children diagnosed with special needs, based on the support and manpower they have available. Still, children with mild to moderate special needs are usually accepted.

\section{Special schools and inclusive programs}

Children with special needs are educated in special education schools, also known as early intervention centers. They must first be diagnosed by specialists, who will determine the severity of their disabilities, before they receive intervention (Nah et al., 2021). Early intervention centers are run by Voluntary Welfare Organizations, and include a team of early intervention professionals, therapists, psychologists, and social workers who offer a holistic program, which targets a child's developmental, social, language, communication, and self-help skills (Poon \& Yang, 2016). Teachers here have received specialized training in early intervention through an advanced diploma (Poon \& Yang, 2016). The program hours are short, ranging from two to four hours a day, two 
to five days a week, depending on the severity of the child's disability. This allows for children to attend mainstream preschool in the daytime or afternoon.

One form of inclusive education practiced in Singapore is the Integrated Childcare Program (ICCP) for children diagnosed with mild to moderate disabilities, such as autism spectrum disorder, developmental delay, physical disabilities, hearing or visual impairment (Poon \& Yang, 2016). Although it does not offer any intervention services (Nah et al., 2021), children with special needs gain opportunities to learn, play and socialize with typically developing peers in mainstream preschools, and preparation for future entry into mainstream education. The 13 preschools participating in the program receive additional grants to deploy more teachers to support children with special needs (Poon \& Yang, 2016). There will also be at least one teacher trained in special needs to provide extra guidance and support.

Another initiative to support children with special needs in mainstream preschool is the Developmental Support Program (Poon \& Yang, 2016). The program offers 10 weekly sessions (Poon \& Yang, 2016) where early intervention professionals will coteach alongside the preschool teacher (Nah et al., 2021). It is currently being offered to children who have made sufficient progress in early intervention centers, where early intervention professionals will support the child in his/her mainstream preschool, so that they can adapt to the new setting with large class sizes and high teacher-child ratio (Nah et al., 2021).

\section{Steps towards inclusive preschool education}

While the better solution in moving towards inclusion would be to reduce the childteacher ratio (Nonis et al., 2016), this is likely not possible in Singapore's preschool, given the high demand for preschool places as well as high attrition rate of preschool teachers (Lim, 2017). To counter the issue of manpower shortage and lack of training in special needs, the government has instead opted to increase manpower, in the form of Learning Support Educators (Tan, 2017). Learning Support Educators are trained early interventionists who provide intervention whilst supporting preschool teachers, under the existing Developmental Support Program. However, it is concerning that the government is only building a pool of 200 Learning Support Educators over five years (Tan, 2017), which will not be enough to provide support to all the preschools in Singapore.

Another new initiative to improve inclusion in preschools is the appointment of inclusion coordinators in all preschools, starting from 2023 (Co, 2021). Inclusion coordinators are picked from each preschool's existing staff and will be trained to identify and support children with special needs. They will also be tasked to support teachers and parents by providing early intervention resources or support. While it signals a promising move to improve early detection and hence early intervention for children 
who require support, this new initiative will not work towards supporting teachers with managing children with special needs. As only one or two teachers from each preschool are picked to undergo training on identifying children with special needs and early intervention resources, it would mean that the remaining preschool teachers in Singapore remain untrained and unequipped to manage an inclusive class.

Singapore has also begun piloting a new Inclusive Support Program in a few preschools for children who need medium levels of early intervention support (Co, 2021). In this program, full-time early intervention professionals and visiting allied health professionals will work alongside preschool teachers, hence integrating early intervention and early childhood education and care services (Ministry of Social and Family Development, 2021). Preschool teachers and early intervention professionals will collaborate to create an inclusive environment, also ensuring that lessons are catered to children's different learning abilities. Children with special needs will also be supported through an individualized education plan, via in-class support or pullout sessions depending on their need. This program aims to provide more integrated support for families with parents being updated and involved in their child's progress and development in preschool (Ministry of Social and Family Development, 2021). This program seems the most promising in achieving Singapore's vision for inclusive education by leveraging on the expertise of existing early intervention professionals to support preschool teachers with inclusion. Still, preschool teachers will need to receive more in-service and pre-service training on special needs should this program be successfully expanding to create more inclusive preschools in the future.

Although the government has come up with new initiatives to push for inclusive preschool education, there exist inherent issues that may undermine Singapore's efforts to achieve true inclusion which will be discussed in the next section.

\section{Challenges with inclusive preschool education in Singapore}

\section{Battling conservative mindsets}

In 2017, Singapore's Minister for Social and Family Development, Tan Chuan-Jin announced that the government is looking into the practicality of an inclusive preschool model (Tan, 2017). He highlighted that apart from the government's current initiatives, there has to be a change in mindset on how children with disabilities can be supported. For years, the care of persons with disability has been considered to be the responsibility of their family, with institutional support only seen as a secondary option (Ang et al., 2021). Hence, there exist issues with how persons with disability can be supported and who shoulders responsibility. Currently, families receive support from various Voluntary Welfare Organisations (VWOs), which receive funding from the 
government (Tan, 2017). Nevertheless, the amount of support these VWOs can offer is limited and parents ultimately are the ones struggling to search for a mainstream preschool that can accept their child and also provide the necessary support that the preschool requires, such as shadow teachers. Therefore, policy makers and key stakeholders have to consider the question of who should shoulder the responsibility for ensuring that children with special needs are being enrolled into mainstream preschools.

Moreover, the traditional perception of disabilities as a 'defect' still perpetuates in society even today (Ang et al., 2021). The disability of the individual is emphasized, instead of their strengths and capabilities, and admitting a child into a special school serves to further define them by their disabilities. Furthermore, there has to be a paradigm shift from the traditional view of inclusion from a charity or social welfare perspective (Opertti et al., 2013), where persons with disabilities are disadvantaged and have to be helped. Societies should inculcate a rights-based perspective (Opertti et al., 2013) where all children have the right to education in mainstream schools, as well as a strengths-based perspective (Ang et al., 2021) where the differences and strengths of individuals are celebrated.

It is interesting to note that in Reggio Emilia preschools, children with special needs are referred to as "children with special rights" (Smidt, 2012). This term shows the way that children with disabilities are regarded. They are not seen as disadvantaged, but rather seen as equally capable and competent (Mitchiner et al., 2018). Reggio Emilia preschools are welcoming towards the idea of children being different (Smidt, 2012) and this changes the way disability is seen - the strengths of each child are emphasized instead of their disabilities. In addition, children with special rights are given precedence in admission to preschools (Smidt, 2012) which differs from mainstream schools which exclude children with special needs. Reggio Emilia's inclusive practices hence serve as a great example in showcasing the idea of education for all where children with special needs are not excluded and are a true part of the community, and how Singapore can move forward with its inclusive efforts.

\section{The clash between inclusion and meritocracy}

The long-standing perception of disability as a defect has its roots in the lack of exposure to and hence understanding of persons with disability as well as Singapore's educational culture which is meritocratic and hence highly competitive (Ang et al., 2021). While meritocracy can be positively seen as a means for people to climb up the ladder in a society based on their achievements, it also means that people with various conditions are unable to move out of poverty (Ang et al., 2021). Furthermore, it can be challenging to instill the need for Singapore to progress to a more caring and inclusive society (Third Enabling Masterplan Steering Committee, 2017), when the need 
to perform academically is so highly emphasized in schools. There is hence a need to reconsider the current education system so that those who are disadvantaged are not left behind (Ang et al., 2021).

This also calls for a re-evaluation of the purpose of education in Singapore, as even preschools are slowly becoming more academic-centric especially Kindergarten (Bautista et al., 2016). If schools are merely pushing for academic excellence, it would be difficult for children with special needs to truly feel included or gain a sense of belonging, especially when they when they cannot cope or perform (Nonis et al., 2016; Li \& Chong, 2011). As inclusive education calls for reviewing the curriculum, the question remains as to whether children with special needs are receiving the quality education that they need to maximize their potential (Third Enabling Masterplan Steering Committee, 2016). While the goal for typically developing children is academic achievement: is this what children with special needs really need in order to navigate society as independent adults? Should the main purpose of Singapore's education system be to produce academic excellence or lay a path towards a more caring and inclusive society? Policy makers need to consider how to proceed with the current education system should Singapore want to move towards an inclusive education model.

\section{Conclusion}

Inclusive education is a big challenge especially in Singapore because of structural barriers, such as high child-teacher ratio, lack of support and training, traditional mindsets, and the foundations of our educational system. It requires changes on all levels, beginning with policy makers in steering the nation towards a vision of inclusion, to providing inclusive environments in schools and changing the mindsets of individuals. Teachers especially play a huge role in ensuring the success of including children with special needs. Nevertheless, even while changes are made on all levels, there will still be challenges faced on the ground, especially when children with severe disabilities or who are aggressive are accepted into mainstream schools. These issues will hence require another round of re-evaluation of the barriers towards inclusion to ensure that inclusive education is successful. Singapore's current pilot Inclusive Support Program has shown progress in Singapore's striving for inclusive education, although it remains to be seen if preschools will be able to support children with severe disabilities in the future. Nevertheless, through inclusive preschool education, children can better understand their peers with special needs. It is hoped that this will serve to change the mindsets of the future generations on how persons with disability are perceived, for schools to be truly inclusive. 


\section{Personal Reflection}

Having worked with some children with special needs as a preschool teacher in a mainstream class, this topic is of particular interest to me as I constantly reflected on how inclusion and inclusive education can be improved. While researching, the challenges and proposed changes in other papers resonated with the experiences and challenges that I faced. While it is easy to write a paper on how inclusion can be introduced successfully, it is certainly not easy at all when you are implementing it. Strategies you find or hear may not work. What was particularly surprising to me was watching one child behave completely differently in the special school. It would have been very beneficial if early intervention professionals could have worked with me in my class, sharing their expertise and knowledge. Nonetheless, it is still heartening to see that many teachers are supportive of inclusive efforts although we lack the knowledge and expertise to manage and provide quality education for children with special needs. As Singapore's next Enabling Masterplan will be released at the end of 2021 , it would be positive to see if more recommendations can be made for barriers to inclusion in schools to be progressively removed and inclusive preschools to become the new norm.

\section{References}

Ainscow, M. (2000). The next step for special education: Supporting the development of inclusive practices. British Journal of Special Education, 27(2), 76-80.

Akalin, S., Demir, S., Sucuoğlu, B., Bakkaloğlu, H., \& Işcen, F. (2014). The Needs of Inclusive Preschool Teachers about Inclusive Practices. Eurasian Journal of Educational Research, (54), 39-60.

Andresen, R. (2013). Visions of what inclusive education can be - With emphasis on kindergartens. European Early Childhood Education Research Journal, 21(3), 392-406. DOI: 10.1080/1350293X.2013.814359.

Ang, L., Lipponen, L., \& Lim, S. (2021). Critical reflections of early childhood care and education in Singapore to build an inclusive society. Policy Futures in Education, 19(2), 139-154. DOI: $10.1177 / 1478210320971103$.

Bautista, A., Ng, S., Múñez, D., \& Bull, R. (2016). Learning areas for holistic education: kindergarten teachers' curriculum priorities, professional development needs, and beliefs. International Journal of Child Care and Education Policy, 10(8), 1-18. DOI: 10.1186/s40723016-0024-4.

Brodzella, K., Ottley, J., Jung, J., \& Coogle, C. (2018). Interventions and Adaptations for Children with Autism Spectrum Disorder in Inclusive Early Childhood Settings. Early Childhood Education Journal, 46, 277-286. DOI: 10.1007/s10643-017-0859-5. 
Co, C. (2021, March 5). All pre-schools to have inclusion coordinator to identify and support children with developmental needs. Retrieved from Channel News Asia: https://www. channelnewsasia.com/singapore/pre-schools-inclusion-coordinator-children-developmental-needs-307921.

Garfinkle, A, \& Schwartz, I. (2002). Peer Imitation: Increasing social interactions in children with autism and other developmental disabilities in inclusive preschool classrooms. Topics in Early Childhood Special Education, 22(1), 26-38.

Justice, L., Logan, J., Lin, T., \& Kaderavek, J. (2014). Peer Effects in Early Childhood Education: Testing the Assumptions of Special-Education Inclusion. Psychological Science, 25(9), 722-1729. DOI: 10.1177/0956797614538978.

Karlsudd, P. (2021). Promoting Diversity and Belonging: Preschool Staff's Perspective on Inclusive Factors in the Swedish Preschool. Education Sciences, 11(104), 1-19. DOI: 10.3390/educsci11030104.

Li, J., \& Chong, J. (2011). Social Skills of Mainstream Kindergarten Children with Special Needs in Singapore. Journal of Reading and Literacy, 3, 24-38.

Lipponen, L., \& Ang, L. (2019). Vital Voices for Vital Years 2: Perspectives on Early Childhood Development in Singapore. Lien Foundation.

Mitchiner, J, Batamula, C., \& Kite, B. (2018). Hundred Languages of Deaf Children: Exploring the Reggio Exploring the Reggio Emilia Approach in Deaf Education. American Annals of the Deaf, 163(3), 294-327. DOI: 10.1353/aad.2018.0021.

Nah, Y., Chen, M., \& Poon, K. (2021). Supporting Individuals With Autism Spectrum Disorder in Singapore. Intervention in School and Clinic, O(0), 1-7. DOI: 10.1177/10534512211032 911.

Nonis, K. (2006). Integrating Children with Special Needs: Singapore Preschool Teachers Share Their Feelings: A Preliminary Investigation. The Journal of the International Association of Special Education, 7(1), 4-10.

Nonis, K., Chong, W., Moore, D., Tang, H., \& Koh, P. (2016). Pre-school teacher's attitudes towards inclusion of children with developmental needs in Kindergartens in Singapore. International Journal of Special Education, 31(3), 1-30.

Opertti, R., Walker, Z., \& Zhang, Y. (2013). Inclusive Education Education: From Targeting Groups and Schools to Achieving Quality Education as the Core of EFA. In L. Florian, (Ed.), The sage handbook of special education: Volume Two (pp. 149-170). SAGE Publications.

Poon, K., Ng, Z., Wong, M., \& Kaur, S. (2016). Factors associated with staff perceptions towards inclusive education in Singapore. Asia Pacific Journal of Education, 36(1), 84-97. DOI: 10.1080/02188791.2014.922047.

Smidt, S. (2012). Introducing Malaguzzi: Exploring the life and work of Reggio Emilia's founding father. London: Routledge.

Tan, J. (2017). Ministry looking at inclusive preschool model for special needs children. https:// search.proquest.com/docview/1999157816?accountid=12834. 
Tan, R., \& Perren, S. (2021). Promoting peer interactions in an inclusive preschool in China: what are teachers' strategies? International Journal of Inclusive Education, 1-17. DOI: 10.1080/13603116.2021.1879955.

Third Enabling Masterplan Steering Committee. (2016). Third Enabling Masterplan 20172021: Caring Nation, Inclusive Society. Third Enabling Masterplan Steering Committee.

Walker, Z., \& Musti-Rao, S. (2016). Inclusion in High-Achieving Singapore: Challenges of Building an Inclusive Society in Policy and Practice. Global Education Review, 3(3), 28-42.

Weng, C., Walker, Z., \& Rosenblatt, K. (2015). Special education teachers' attitudes toward including students with SEN in mainstream primary schools in Singapore. Asia Pacific Journal of Developmental Differences, 2(1), 63-78. DOI: 10.3850/S2345734115000216.

Wong, M, Poon, K., Kaur, S., \& Ng, S. (2015). Parental perspectives and challenges in inclusive education in Singapore. Asia Pacific Journal of Education, 35(1), 85-97. DOI: 10.108 0/02188791.2013.878309.

Xie, H., Nah, Y., Yang, X., Wilhelmina, S., \& Poon, K. (2021). Early Childhood Intervention: What We Know and Where We Are Headed. National Institute of Education.

Yang, C., \& Rusli, E. (2012). Teacher Training In Using Effective Strategies For Preschool Children With Disabilities In Inclusive Classrooms. Journal of College Teaching \& Learning, 9(1), 53-64.

Yeo, L., Chong, W., Neihart, M., \& Huan, V. (2016). Teachers' experience with inclusive education in Singapore. Asia Pacific Journal of Education, 36(1), 69-83. DOI: 10.1080/021887 91.2014.934781.

Yeo, L., Neihart, M., Tang, H., Chong, W., \& Huan, V. (2011). An inclusion initiative in Singapore for preschool children with special needs. Asia Pacific Journal of Education, 31(2), 143-158. DOI: 10.1080/02188791.2011.566990. 